\title{
L’agriculture périurbaine à Oran (Algérie) : diversification et stratégies d'adaptation
}

\author{
Hadj Mohammed Maachou et Tayeb Otmane* \\ Laboratoire EGEAT, Université d'Oran 2, Mohamed Benahmed, Algérie
}

\begin{abstract}
Résumé - Oran, ville méditerranéenne dynamique et seconde agglomération algérienne, a évolué selon un processus d'urbanisation diffuse. Ses franges rurales périurbaines, aux contours flous, lieux d'importantes transformations, sont actuellement des espaces de production agricole. Une redéfinition de l'agriculture périurbaine s'opère par des initiatives individuelles qui se traduisent par une diversification agricole : développement de cultures à forte plus-value, maraîchères, arboricoles et ornementales. Les entretiens directifs menés auprès des agriculteurs périurbains ont permis d'expliquer les facteurs qui sont à l'origine de ces transformations. Le profit tiré des cultures pratiquées est en lien avec l'accroissement de la demande citadine, l'intensification agricole étant une réponse à la précarisation foncière engendrée par l'urbanisation et par le morcellement excessif des propriétés.
\end{abstract}

Mots clés : agriculture périurbaine / reconfiguration foncière / stratégies d'adaptation / diversification / Algérie

\begin{abstract}
Peri-urban agriculture in Oran (Algeria): diversification and adaptation strategies. Dynamic Mediterranean and second Algerian city, Oran has faced a diffuse urbanization process. Its rural fringe, just at the outskirts of the city, is today an area where important changes take place in the agriculture production system. A redefinition of peri-urban agriculture is carried out by individual initiatives that result in agricultural diversification: developing high added-value crops, vegetables, and ornamental trees. The structured interviews carried out with the peri-urban farmers allowed identifying the factors that are causing these changes. The profit issued from the crops is in line with the increase in the urban demand; agricultural intensification is a response to the land insecurity created by urbanization and the excessive fragmentation of properties.
\end{abstract}

Keywords: peri-urban agriculture / land reconfiguration / adaptation strategies / diversification / Algeria

\section{Introduction}

L'agriculture périurbaine fait l'objet d'un intérêt renouvelé de la part des chercheurs; elle est abordée sous l'angle de sa fonction alimentaire dans les pays du Sud (Lavergne, 2004) et sous l'angle de sa multifonctionnalité dans les pays du Nord (Donadieu et Fleury, 1997). Au Maghreb, et particulièrement en Algérie, la recherche se focalise sur les questions urbaines ; l'agriculture périurbaine, peu abordée, est approchée sous l'angle de la question foncière conflictuelle (Bendjaballah Boudemagh, 2013 ; Boudjenouia et al., 2006 ; Elloumi, 2011). À Oran, l'agriculture périurbaine a connu des transformations successives en passant de la monoculture viticole à la monoculture céréalière puis à la diversification par l'émergence d'une agriculture maraîchère et horticole. Ces transformations résultent de réformes foncières, de croissance et pression urbaines, mais aussi de stratégies d'agriculteurs. Dans ce contexte, Oran représente un cas particulier d'une forme à la

\footnotetext{
*Auteur de correspondance : otmanet1@yahoo.fr
}

fois de résistance et de renouveau de l'agriculture périurbaine en Algérie. Cette contribution tente d'analyser ces transformations et d'approcher les liens entre Oran et son agriculture périurbaine.

Depuis 1972, Oran, deuxième ville d'Algérie (Fig. 1), s'est étalée selon un rythme de croissance urbaine rapide en artificialisant 110 ha en moyenne par an (Trache, 2010). Elle a reporté son urbanisation sur les agglomérations limitrophes (Maachou, 2012). Celles-ci sont donc devenues en quelques années des banlieues urbaines, englobées dans la dynamique de l'agglomération. Il en a résulté la constitution d'une métropole de plus d'un million d'habitants en 2008, regroupant six chefslieux de communes (Oran, Es Senia, Bir El Djir, Sidi Chami, El Kerma et Hassi Bounif) et une dizaine de fragments d'habitat de différentes tailles.

Cette périurbanisation a produit une mosaïque d'espaces urbains et agricoles, ayant des relations complexes, à la fois conflictuelles et complémentaires, et des limites imprécises entre espaces ruraux et urbains. Certes, l'urbanisation massive a en partie détruit des cultures, mais elle a également engendré des transformations et adaptations de l'agriculture des franges 


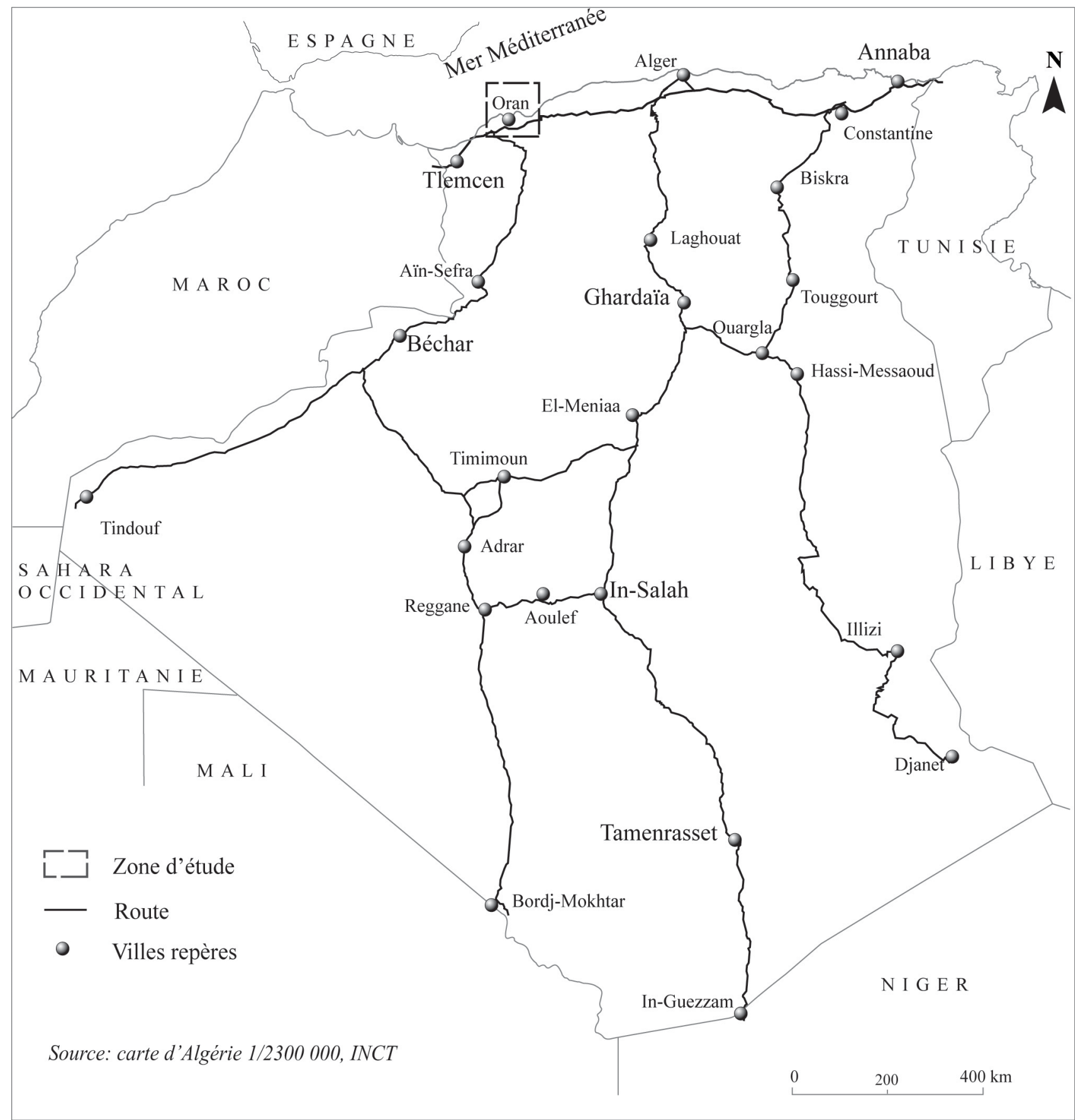

Fig. 1. Localisation de la zone d'étude.

Fig. 1. Location of the study area.

urbaines, en introduisant de nouvelles cultures et de nouveaux circuits de commercialisation.

Ce travail est le résultat d'une vingtaine d'entretiens directifs menés en 2012 auprès des agriculteurs et des pépiniéristes rencontrés dans les exploitations de la zone périurbaine. Nous les avons interrogés sur des questions relatives à l'exploitation agricole et à son équipement, à la propriété foncière, aux motivations du choix des cultures, aux modes de faire-valoir, à la pression urbaine et à la commercialisation. D'autres entretiens ont été menés auprès des acteurs institutionnels (collectivités locales et services agricoles) pour connaître leur vision sur l'agriculture périurbaine.

En parallèle, et pour mieux mesurer les transformations paysagères, nous avons élaboré une cartographie d'occupation du sol périurbain en nous basant sur un relevé de terrain. Cette analyse est également étayée par les statistiques des organes officiels : l'Office national des statistiques (ONS) et la Direction des services agricoles de la wilaya d'Oran (DSA). 


\section{Des formes d'appropriation foncière successives et rapides, sources d'instabilité}

Plus de la moitié de la superficie totale de l'ensemble des communes (30 979 ha) qui composent l'agglomération d'Oran est constituée de surfaces agricoles utiles (16510 ha). Les deux tiers de ces surfaces se localisent au sein des communes du Sud (El Kerma, Sidi Chami et Hassi Bounif), l'autre tiers est partagé entre les communes du Nord : Oran, Es Senia et Bir El Djir.

Les terres agricoles en propriété publique entourant l'agglomération oranaise forment l'essentiel du potentiel agricole productif. Cette propriété a été constituée de terres, souvent les plus fertiles, appartenant auparavant aux colons et nationalisées par l'État indépendant. Leur exploitation s'est faite, et se fait toujours, avec un droit d'usage. Elle a évolué depuis l'Indépendance, passant de l'autogestion au début de l'Indépendance à l'exploitation coopérative socialiste dans le cadre de la révolution agraire pendant les années 1970, puis à l'exploitation individuelle et collective après 1987.

Avant 1987, les terres en propriété publique des six communes appartenaient à 25 domaines autogérés socialistes (DAS), de superficie variant entre 400 et 500 ha, qui avaient éclaté après la restructuration de 1987 en 166 exploitations agricoles collectives (EAC) et 1076 exploitations agricoles individuelles (EAI) couvrant respectivement 7380 ha et 5988 ha. Les EAC sont attribuées à 1021 agriculteurs. Elles sont organisées en groupes de cinq ou six, leur taille varie de 25 à $126 \mathrm{ha}$; les plus grandes sont céréalières. Les EAI font 5 ha en moyenne. Le secteur privé ne représente qu'une partie infime de la surface agricole utile.

Les restructurations foncières successives entamées depuis 1963, en moyenne une par décennie, ont conduit à l'instabilité dans l'exploitation agricole et ont influé sur l'engagement efficient des agriculteurs pour le travail de la terre (Ahmed Ali, 2011). La loi 10-03 du 15 août 2010 vient de modifier la perpétuité de jouissance accordée par la loi 87-19 en concession pour une durée de 40 ans. Elle rompt avec le collectivisme hérité, imposé par la période antérieure. Elle offre au concessionnaire la possibilité de prendre un crédit hypothécaire et de conclure des partenariats avec des investisseurs nationaux. Les procédures administratives sont en cours d'élaboration et les retombées de cette loi vont davantage favoriser le regroupement des exploitations agricoles émiettées de façon formelle ou informelle et le faire-valoir indirect.

La précarisation du statut foncier engendrée par ces réformes est ici accentuée par la proximité d'une grande agglomération dynamique, ce qui explique que des exploitations agricoles soient travaillées en faire-valoir indirect. Trois jeunes agriculteurs interviewés, venant des wilayas voisines (Mascara, Chlef et Aïn Defla), louent des terres dans le nord de la commune de Sid Chami d'une manière informelle et pratiquent les cultures maraîchères en plein champ ou sous serres.

Jusqu'en 1990, l'État a monopolisé le transfert et la gestion du foncier urbain public et privé pour satisfaire les besoins des agglomérations. Depuis, le marché foncier a été libéré par la loi d'orientation foncière (90-25), mais l'État continue toujours à transférer sans peine le foncier agricole à l'urbanisation étant donné que les terres entourant la majorité des agglomérations lui appartiennent. Cependant, malgré une pression urbaine forte à Oran, certains propriétaires privés (agriculteurs et bourgeoisie citadine) conservent leurs propriétés foncières agricoles.

\section{Les transformations de l'espace agricole périurbain oranais: de la monoculture à la polyculture}

La surface agricole des communes qui composent l'agglomération oranaise est dominée par les cultures en sec notamment céréalières ( $85 \%$ de la SAU). L'essentiel de cette superficie était occupé à l'Indépendance par le vignoble (Fig. 2), une culture héritée de la période coloniale. Les effets de l'embargo imposé par la France au début de 1967 sur l'importation de vins algériens et la faible consommation locale ont mis cette culture en difficulté. En conséquence, $90 \%$ de la superficie réservée au vignoble (343000 ha) ont été arrachés dans le territoire national entre 1963 et 1980 , et des milliers d'emplois ont été perdus ; la vigne fut remplacée progressivement par la céréaliculture extensive. De par ses aptitudes naturelles favorables à la viticulture, l'Ouest algérien a été le plus touché par cette opération d'arrachage. Cependant, la destruction des vignobles à Oran fut initiée bien avant l'Indépendance en remplaçant les fermes viticoles par des lotissements (Benkada, 2001).

Le paysage agraire entourant Oran a ainsi été progressivement uniformisé et a perdu en diversité. Dès le début des années 1970, période de lancement de la révolution agraire, les céréales sont devenues l'élément de base de ces paysages, bien qu'étant une culture en sec à faible rendement, tributaire d'un climat méditerranéen semi-aride aux précipitations irrégulières.

La réorganisation du secteur agricole de 1987, à orientation libérale, a ouvert le chemin à l'initiative individuelle - le passage du travail collectif au travail individuel. Même si les EAC gardent leur statut collectif, en pratique les attributaires ont fait des partages officieux sur le terrain pour être libres dans le travail et le choix des cultures. Ce changement a été timide au départ, mais il s'est affirmé progressivement en diversifiant les cultures et en modifiant les modes de faire-valoir. L'occupation du sol par l'agriculture s'est beaucoup plus diversifiée aux abords de l'agglomération d'Oran.

\section{Le renouveau de l'agriculture périurbaine}

\subsection{L'essor et la diversification du maraîchage}

Actuellement, la superficie agricole irriguée représente environ $15 \%$ de la SAU, dont la partie la plus importante se trouve au sein des communes de Sidi Chami, de Hassi Bounif et d'Es Senia avec respectivement 693 ha, 622 ha et 557 ha. Dès l'an 2000, à la faveur de l'utilisation de l'eau des nappes phréatiques et du fait de l'augmentation de la demande en produits maraîchers, les superficies irriguées ont commencé à s'accroître en affichant une nouvelle dynamique après une longue période de stagnation, voire de recul de la production agricole. Des cultures de saison et hors-saison, ainsi que des cultures pérennes, prennent place dans le paysage oranais (Fig. 3). 


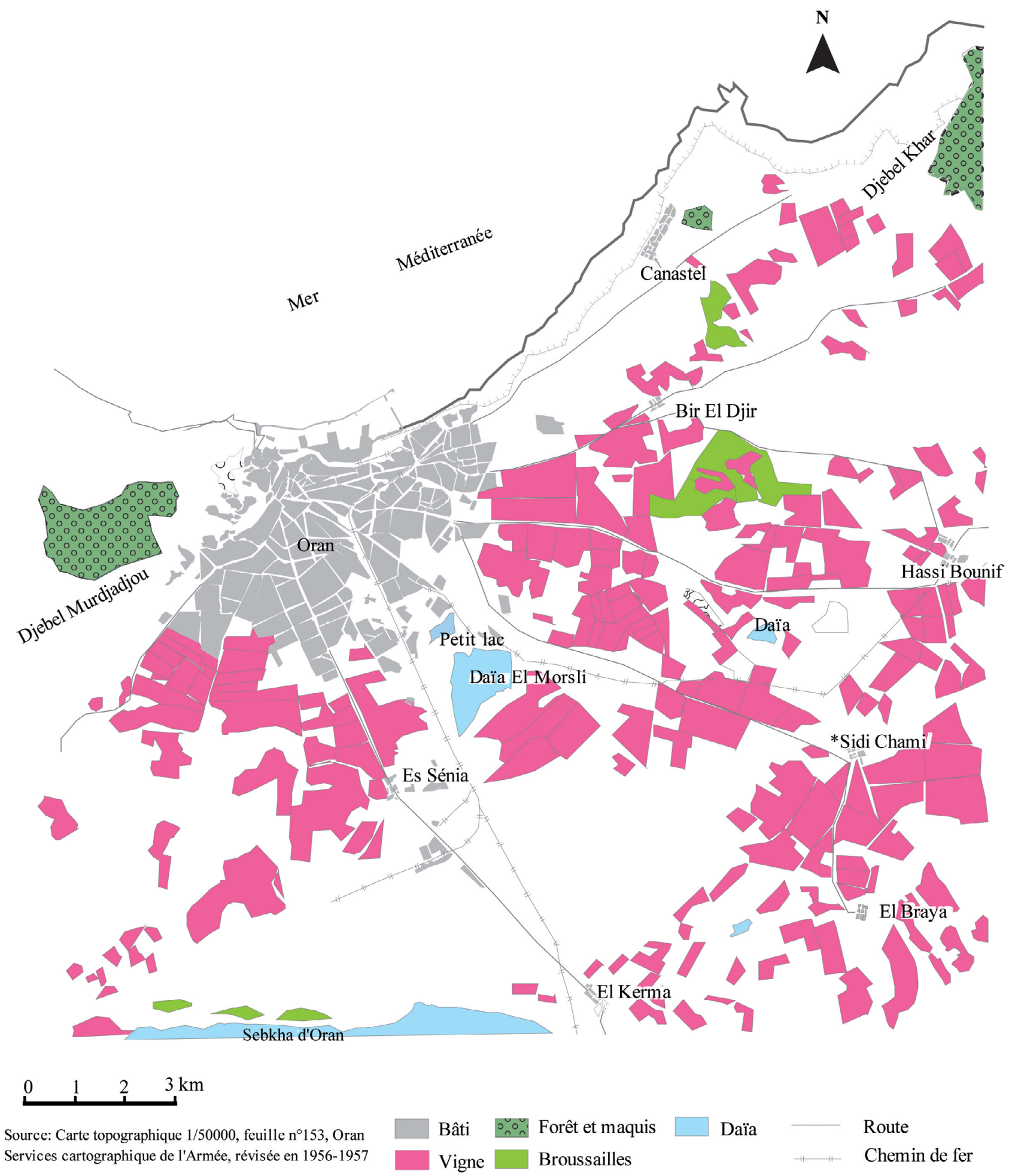

Fig. 2. La répartition du vignoble à Oran en 1957.

Fig. 2. The distribution of the vineyard in Oran in 1957.

Différents facteurs conjugués sont à l'origine de cette nouvelle dynamique agricole. L'immédiat arrière-pays d'Oran participe à la satisfaction des besoins en produits maraîchers frais par effet de proximité. L'amélioration du niveau de vie de la population algérienne a, en outre, permis d'accroître cette demande et donc d'assurer des débouchés locaux aux producteurs périurbains.

Une gamme diversifiée de produits maraîchers est cultivée, quelques cultures sont saisonnières (petit-pois, fève, etc.) ou spéculatives (pastèque, melon); elles dépendent des 


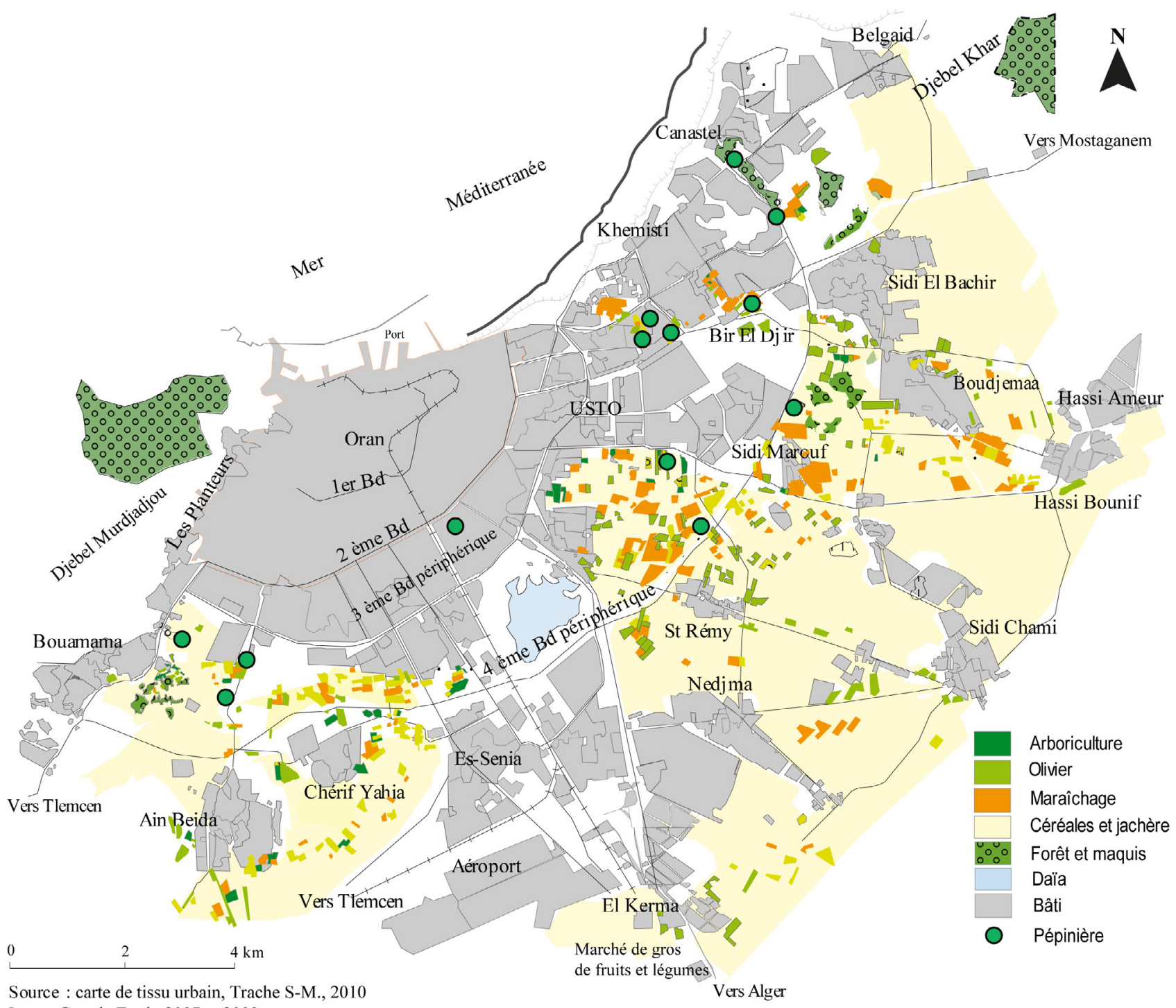

Image Google Earth, 2007 et 2009

Enquête de terrain, 2012

Fig. 3. L'agriculture dans les franges urbaines d'Oran.

Fig. 3. Agriculture in the urban fringe of Oran.

précipitations hivernales et printanières, mais elles bénéficient aussi d'une irrigation de soutien en cas d'insuffisance de pluies. D'autres cultures, produites au cours de l'année ou hors-saison, sont pratiquées sous irrigation en plein champ (pomme de terre, carottes, tomates...) et dans des serres. Des exploitations agricoles combinent plusieurs cultures, tandis que d'autres se sont spécialisées sur des produits à écoulement rapide tels que les épinards et les plantes aromatiques de cuisine (persil, coriandre, cerfeuil, menthe, etc.), cultivées toute l'année en profitant de l'humidité maritime et de l'absence de gel. La taille des parcelles cultivées varie entre 1 et 3 hectares en moyenne. Excepté les labours qui se font par des moyens mécaniques, le travail demeure exclusivement manuel. Les agriculteurs pratiquent la jachère dans les deux types d'occupation, maraîchère et céréalière.

Deux systèmes d'irrigation sont utilisés. Le premier est traditionnel, par irrigation gravitaire. Le deuxième, plus moderne, utilise des réseaux de goutte-à-goutte, ce qui révèle une mutation des techniques.

La plasticulture, une agriculture intensive sous serre, a été introduite depuis quelques années dans le paysage agricole périurbain d'Oran (Fig. 4). Les cultures pratiquées sont généralement hors-saison, et à forte valeur ajoutée, telles que les tomates, poivrons, piments ou concombres. De jeunes agriculteurs, issus de familles paysannes, pourvus d'un savoirfaire en la matière, originaires du centre du pays (notamment Chlef, Ain Defla et Blida), sont venus investir dans ce créneau porteur, assurés de débouchés urbains. D'après ces agriculteurs, ce type de culture permet des gains appréciables; le rendement est de 5 à 10 fois supérieur à celui des cultures de plein champ. Un investissement de base de 50000 à 70000 DA par serre et par an, procure dans des conditions favorables un gain net entre 250000 et $300000 \mathrm{DA}$ $(1000 \mathrm{DA}=8 €)$. L'exploitant qui possède une dizaine de 


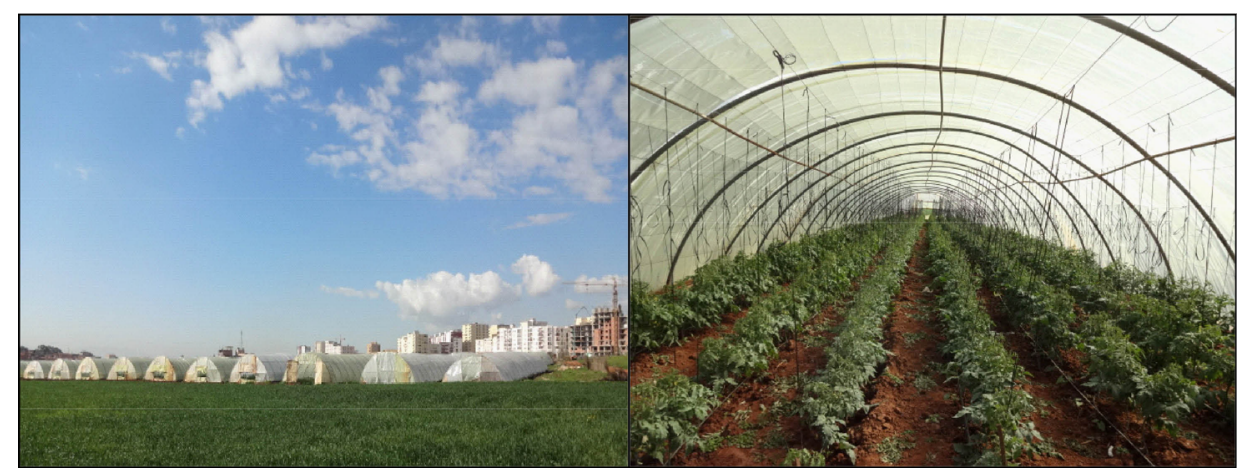

Fig. 4. Le développement de la plasticulture en franges urbaines d'Oran (2012).

Fig. 4. The development of the plasticulture in urban fringes of Oran (2012).

serres gagne environ 13 fois le salaire national minimum garanti (SNMG). Les installations mises en place au début pouvaient donc être amorties en une seule année.

D'après nos interviews, les deux formes de faire-valoir, direct et indirect, sont pratiquées. De jeunes descendants de familles paysannes prennent la relève en travaillant dans les exploitations maraîchères. D'autres exploitants interrogés, ayant un bail oral (arrangement entre attributaires et nouveaux exploitants pour contourner la loi 87-19), sont venus de Mascara, de Chlef, d'Aïn Defla et de Blida. Ils ont loué des exploitations agricoles et de l'eau, ensemble ou séparément. Ce dernier cas est celui d'un agriculteur qui a été dans l'obligation de ramener l'eau d'une localité distante de $3 \mathrm{~km}$ pour irriguer une vingtaine de serres. La location se fait par campagne agricole, qui dure en moyenne six mois, à raison de 50000 DA par hectare. Cette attitude peut être expliquée en partie par la nature de cette propriété qui est toujours publique, donc sans engagement agricole réel de son attributaire ; elle peut aussi être expliquée par l'orientation des attributaires vers le salariat urbain.

\subsection{L'extension de l'arboriculture}

L'arrière-pays d'Oran a toujours été occupé en partie par l'arboriculture, le vignoble, l'olivier et les agrumes. L'avènement du Plan national de développement agricole (PNDA), dans les années 2000, a donné un nouveau souffle aux exploitations agricoles. On a assisté à la multiplication des parcelles d'olivier (Fig. 5) ; les subventions accordées par l'État dans le cadre de ce plan ont en effet permis la fourniture de l'équipement hydro-agricole, la plantation et la mise en place du réseau de goutte-à-goutte. Cette reconversion des systèmes de culture s'est opérée dans l'ensemble du territoire national, permettant ainsi une modernisation de milliers d'exploitations agricoles. Développer une culture pérenne au contact de l'urbain ne relève pas de l'action fortuite. D'une part, ce type de culture rustique est actuellement très rentable sur le marché national, en raison d'une forte demande qui n'est satisfaite qu'en partie. D'autre part, ces plantations sont perçues par certains comme une forme de « résistance à l'avancée du béton »: le transfert des terres occupées par des cultures saisonnières à l'urbanisation est en effet plus aisé et plus rapide que pour des cultures arboricoles, pérennes et plus coûteuses. Pour d'autres agriculteurs, la plantation arboricole est un moyen de bénéficier des largesses de l'État; le financement de cette culture a été généreux, et par ailleurs, ces espaces cultivés constituent une carte intéressante de négociation en cas de transaction foncière urbaine. Les parcelles arboricoles, surtout oléicoles, sont elles aussi de taille réduite (1 à $3 \mathrm{ha}$ ).

En fait, le paysage agricole dans la frange urbaine d'Oran est caractérisé par un morcellement excessif, superposant une occupation diversifiée et discontinue, basée sur la petite irrigation. Cette situation est le reflet de la parcellarisation officielle de 1987 du domaine privé de l'État en EAI, et celle officieuse des EAC par leurs attributaires. En raison de divergences et de conflits, les EAC se sont d'abord subdivisées par arrangement entre leurs membres en EAC plus petites, pour évoluer ensuite vers l'exploitation individuelle (Boukella, 2008 ; Imache et al., 2009). Ce processus de décollectivisation est devenu quasi général en Algérie (Bouchaib et Jouve, 2010).

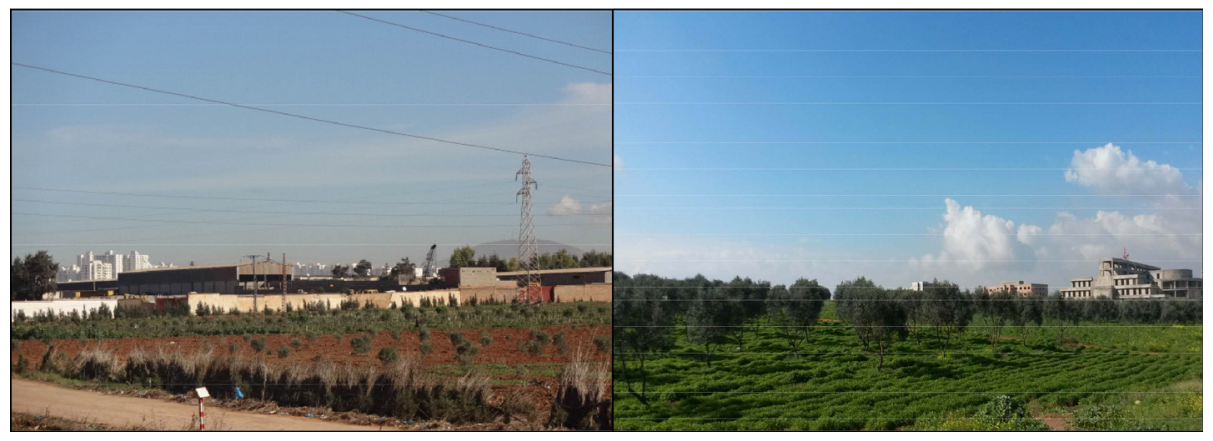

Fig. 5. Des exploitations plantées en olivier à la limite du tissu urbain (2012).

Fig. 5. Farm planted olive trees on the edge of the urban fabric (2012). 


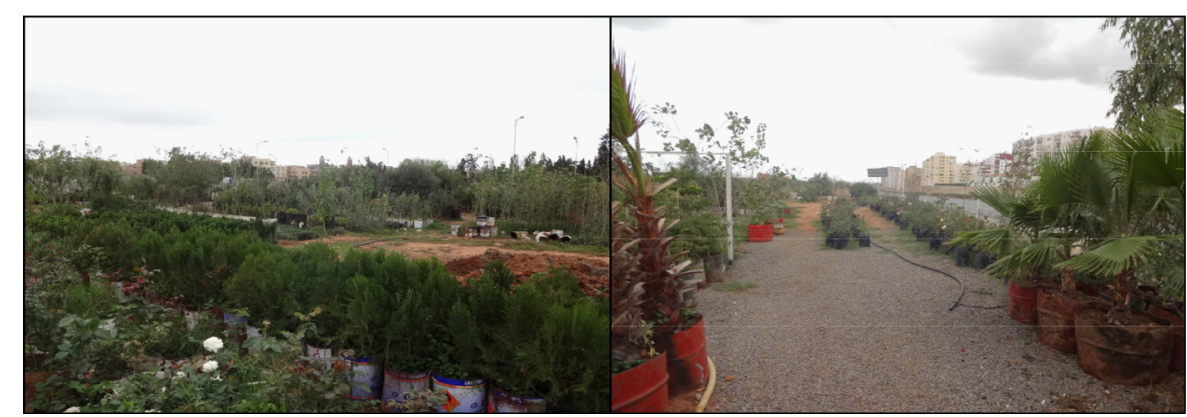

Fig. 6. Des plantes variées produites dans les pépinières d'Oran (2012).

Fig. 6. Various plants produced in the nurseries of Oran (2012).

\subsection{Le développement des pépinières, une réponse à une demande urbaine}

Une dizaine de pépinières de 1 à 4 ha sont localisées au sein de l'agglomération d'Oran. Elles constituent une nouvelle forme d'agriculture qui a émergé en lien avec la demande récente en plantes ornementales et décoratives. Ce type d'agriculture est le résultat du changement dans les modes de consommation lié à l'amélioration du niveau de vie de la population.

Une gamme très variée de produits est cultivée, allant des fleurs, des plantes ornementales et décoratives jusqu'aux arbres fruitiers (Fig. 6). Des pépinières sont créées et gérées par un personnel oranais plus ou moins qualifié, attaché à ce métier, ou par d'autres pépiniéristes installés récemment, venus de l'Algérois, une région réputée pour son savoir-faire en arboriculture et en culture de fleurs. Tel est le cas de quatre pépiniéristes originaires de Blida qui, attirés par la forte demande de la région oranaise, ont loué des petites parcelles (entre 1 et 2 ha) dotées en puits à des EAC. Ils cultivent des plantes sur place et ramènent d'autres du Centre du pays. Les pépiniéristes subviennent aux besoins des collectivités locales pour l'aménagement des espaces verts, des magasins de la ville (notamment ceux de la place Hoche au centre-ville qui sont spécialisés dans la vente des fleurs), des points de vente localisés à proximité des voies de communication et des vergers de la région. Cette production est également destinée aux particuliers qui s'orientent vers la décoration naturelle avec des plantes ornementales et des arbres fruitiers.

Après des décennies d'une urbanisation massive, symbolisée par les grands ensembles collectifs et un développement périurbain important, sans considération d'aspects esthétiques et paysagers (Donadieu et Fleury, 1997), un retour à la nature se dessine à travers cette nouvelle tendance de consommation. En effet, le retour et la reconfiguration de cette nature par la multiplication des espaces verts dans la ville marquent un réel changement de perception des citadins, et des pouvoirs publics, quant à l'environnement urbain. De nombreux terrains vides sont aménagés en espaces verts et dotés de mobilier urbain par les collectivités locales tandis qu'une entreprise publique a été créée, Oran-vert, pour prendre en charge ces lieux de détente. La société civile s'active également par le biais des associations pour sauver ce qui reste des espaces naturels : l'association EsSanaouber, littéralement «les pins », s'est opposée à la réalisation d'un lotissement au sein de la forêt de Canastel à l'est d'Oran et a obtenu gain de cause. La forêt en question est connue pour sa vue panoramique sur la baie d'Oran et constitue un lieu privilégié pour la pratique du sport, elle est actuellement en cours d'aménagement pour la transformer en parc urbain.

\section{Des circuits commerciaux courts et de proximité : une agriculture intrinsèquement liée à la ville}

La commercialisation présente un autre aspect d'interaction entre Oran et sa périphérie, ses modes conditionnent fortement le développement des activités agricoles périurbaines. Plus particulièrement, la ville offre un marché de proximité aux produits agricoles frais à haute valeur ajoutée (Elloumi, 2011).

Hormis la commercialisation des céréales, qui est à la charge de l'État via une filière étatique de mise en marché (contrôlée par la Coopérative des céréales et des légumes secs [CCLS]), des réseaux privés se sont substitués aux structures publiques chargées d'acheminer des biens de consommation depuis la libéralisation du commerce en 1987. Des circuits courts de distribution se greffent aux réseaux commerciaux de l'agglomération oranaise pour écouler la production agricole des franges urbaines. Outre le marché de gros d'El Kerma qui a remplacé les halles de la ville d'Oran, des marchés de fruits et légumes de proximité, formels et informels, se maintiennent dans l'ensemble des entités urbaines de l'agglomération et constituent le réseau sur lequel s'appuient des producteurs, mais aussi des intermédiaires pour mettre en place des circuits courts de commercialisation de fruits et légumes. Ce réseau est renforcé par des ventes directes au consommateur par le biais des réseaux traditionnels, dont les épiceries et le marché hebdomadaire qui se tient les mercredis à Maraval. Un autre réseau informel occupe une place non négligeable et assure la vente aux pieds des bâtiments, aux abords des routes (cité Djamel, Chahid Mahmoud, Saint Rémy, cité El Emir, Belgaid, etc.) et le long $\mathrm{du}$ quatrième boulevard périphérique, aux marges de l'agglomération. Certains surplus de produits tels que la tomate et le piment sont acheminés vers le marché de gros de Mostaganem (Souk El Lile, littéralement, « le marché de nuit »).

Les agriculteurs explorent et combinent souvent toutes les modalités de commercialisation offertes par la demande de l'agglomération. Ils parviennent ainsi à optimiser leurs ventes en fonction de l'évolution de la demande et de la saisonnalité de leurs récoltes. En fonction de la demande urbaine, quelques produits frais tels que les épinards et les plantes aromatiques de cuisine (persil, coriandre, cerfeuil, menthe), sont récoltés et 
vendus chaque jour. Donc, la proximité constitue l'atout principal des producteurs périurbains. Ces circuits courts participent à une reconquête de la fonction alimentaire de proximité de l'agriculture à Oran.

\section{Des perspectives de développement agricole porteuses et des contraintes}

Entre les effets de la pression foncière urbaine et les opportunités liées à la proximité de la ville, l'agriculture périurbaine oranaise s'adapte en développant la petite irrigation et en diversifiant la production. D'une manière générale, ce processus s'inscrit dans une dynamique de réhabilitation des ceintures maraîchères autour des villes algériennes (Alger, Blida, Mostaganem, Tlemcen...), qui n'est pourtant pas issue de politiques publiques souvent orientées vers le développement et la promotion de la vie urbaine. L'agriculture périurbaine à Oran, au même titre que dans d'autres villes maghrébines, n'est pas intégrée dans un projet urbain comme une activité à part entière (Bouraoui, 2001 ; Maachou, 2012). Son développement est intimement lié à des initiatives individuelles d'agriculteurs. Élaboré en 1995, le plan directeur d'aménagement et d'urbanisme du groupement d'Oran (les communes d'Oran, d'Es Senia, de Bir El Djir et de Sidi Chami), au sens de la loi 90-29 qui détermine les règles générales relatives à l'aménagement et l'urbanisme, est censé préserver les terres agricoles et trouver un équilibre entre les usages urbain, agricole et industriel, il a en effet orienté l'extension de l'urbanisation vers l'est pour épargner en partie les terres fertiles à l'ouest, au sud et au sud-est, mais il n'a pas prévu un projet de développement agricole périurbain. En fait, ce sont les initiatives individuelles qui ont introduit l'agriculture dans le circuit actuel de fonctionnement de l'agglomération d'Oran en recourant à l'intensification comme réponse à la consommation des terres agricoles par l'urbanisation ou l'émiettement des propriétés foncières.

La présence d'une main d'œuvre jeune est un bon signe de relève familiale et de retour au travail de la terre. La motivation émanant cette fois-ci de la rentabilité économique de l'agriculture, celle-ci commence à réduire l'écart qui s'est creusé (Dubost, 2002) entre le revenu qu'elle procure et les revenus des autres secteurs économiques. De plus, quelques petits propriétaires ruraux périurbains pratiquent la pluriactivité et recherchent la complémentarité des revenus. Des agriculteurs interrogés déclarent exercer d'autres fonctions dans les périodes creuses entre les campagnes agricoles dans les secteurs du bâtiment, des travaux publics et du tertiaire.

Outre les stratégies individuelles, une volonté publique s'affiche pour développer des cultures irriguées au sud d'Oran. En effet, une station d'épuration des eaux usées urbaines, implantée à El Kerma, est en voie d'achèvement ; elle est censée irriguer théoriquement 4000 ha. Le sud de l'agglomération oranaise sera ainsi voué à une intensification agricole.

Au sein de l'agglomération oranaise, le tissu urbain n'est pas artificialisé d'une manière continue, il reste toujours des interstices de tailles différentes cernés par les constructions ici et là. Ces espaces sont épargnés par l'urbanisation grâce à la forte résistance de leurs propriétaires; ils sont délimités par des clôtures plantées ou construites, et occupés par l'arboriculture, l'horticulture ou le maraîchage, qui peut être pratiqué comme culture d'attente. S'agit-il d'une stratégie de paysans attachés au travail de la terre, de rentiers fonciers qui cherchent une forte plus-value dans le futur ou de citadins aisés en quête d'espaces d'agrément ?

Cependant, cette dynamique agricole connaît des limites, car la tertiarisation redéfinit l'activité globale de la seconde agglomération algérienne et l'urbanisation rapide consomme des terres agricoles dans une Algérie aux terres fertiles réduites et aux conditions climatiques défavorables, caractérisées par la faiblesse des précipitations. Cette situation est exacerbée par les usages croissants de l'eau à des fins domestiques, industrielles et urbaines. Dans l'attente de la satisfaction des besoins de l'agglomération par les eaux de dessalement et de transferts lointains, l'eau des fermes agricoles continue à être vendue par citernes dans les quartiers et met les cultures en péril.

Oran, ville dynamique, est devenue plus attractive et draine des flux humains de tout le territoire national. Par conséquent, une classe fortunée se forme et exerce une pression sur le foncier. De nombreux propriétaires ont construit de nouvelles demeures prestigieuses au sein des parcelles agricoles. Même s'ils préservent leurs vergers, notamment les arbres fruitiers, le mitage de ces espaces ruraux périurbains n'est pas à écarter.

Oran doit donc s'appuyer sur son espace rural pour l'inclure dans ses règles de fonctionnement et éviter un étalement urbain sans discernement (Maachou, 2012). Il apparaît d'autant plus nécessaire aujourd'hui d'appuyer les recommandations du plan directeur d'aménagement et d'urbanisme du groupement d'Oran, élaboré en 1995, qui avait orienté l'urbanisation vers l'est pour épargner en partie les terres fertiles à l'ouest, au sud et au sud-est. Cependant, cela nécessite de penser l'articulation entre les stratégies des producteurs et des habitants cherchant à s'installer en périurbain, avec des politiques publiques claires sur les dimensions agricoles et environnementales.

\section{Conclusion}

Les réformes foncières agricoles successives ont mis l'agriculture algérienne en difficulté, en conservant le statut public des propriétés et en entretenant l'insécurité foncière. La collectivisation de 1987 a abouti au morcellement informel des EAC par arrangement. La loi de 2010 vient d'accorder quelques avantages d'exploitation et d'officialiser le fairevaloir indirect déjà pratiqué. À cela s'ajoute une pression urbaine forte sur les terres agricoles. Néanmoins, et malgré ces nombreuses difficultés, l'agriculture périurbaine semble connaître ces deux dernières décennies un renouveau à Oran ; il ne relève pas encore de préoccupations institutionnelles, mais d'initiatives individuelles et de considérations économiques renforcées par une demande citadine grandissante. Soutenu en partie par l'État, ce renouveau agricole révèle de grandes capacités d'adaptation au changement et au progrès technique. Ainsi, la proximité de l'agglomération oranaise a permis à sa frange périurbaine de gagner en diversité. Plusieurs productions agricoles notamment maraîchères et arboricoles, qui caractérisent cette relance sont développées sur la base de la petite irrigation. L'orientation des citadins vers la décoration naturelle avec des plantes ornementales vient ajouter une autre fonction à l'agriculture périurbaine. Des circuits traditionnels de commercialisation formels et informels sont mis en œuvre pour reconquérir cette fonction alimentaire de proximité. En dépit de l'aspect conflictuel classique rural/urbain, cette 
nouvelle forme d'occupation agricole affiche de nouveaux rapports de complémentarité entre Oran et sa campagne et profile des tendances porteuses.

\section{Références}

Ahmed Ali A. 2011. La législation foncière agricole en Algérie et les formes d'accès à la terre. In: Elloumi M, Jouve A-M, Napoléone C, Paoli JC, eds. Régulation foncière et protection des terres agricoles en Méditerranée. Montpellier (France): CIHEAM, pp. 35-51 (Options Méditerranéennes: Série B. Études et Recherches; $\left.\mathrm{n}^{\mathrm{o}} 66\right)$.

Bendjaballah Boudemagh O. 2013. Politiques urbaines, terres agricoles et marché foncier: quel avenir pour l'agriculture périurbaine à Constantine. Cah. Agric. 22(6): 544-545. doi:10.984/agr.2013.0670.

Benkada S. 2001. Espace périphérique oranais et politiques d'urbanisation (1948-1998). Insaniyat V1(13): 95-104.

Bouchaib F, Jouve A-M. 2010. Le morcellement informel du foncier en Algérie. Cah. Agric. 19(6): 454-459. doi:10.1684/agr.2010.0433.

Boudjenouia A, Fleury A, Tacherift A. 2006. Le statut de l'espace agricole périurbain à Sétif (Algérie) : réserve foncière ou projet urbain ? Cah. Agri. 15(2): 221-226.

Boukella M. 2008. Politiques agricoles, dépendance et sécurité alimentaire. L'Algérie de demain - Relever les défis pour gagner l'avenir. Algérie: Publications Fondation Friedrich Ebert.

Bouraoui M. 2001. L'agriculture, nouvel instrument de la construction urbaine ? Étude de deux modèles agri-urbains d'aménagement du territoire : le plateau de Saclay, à Paris, et la plaine de Sijoumi, à Tunis. Ruralia 08-2001, mis en ligne le 25 janvier 2005, URL : http://ruralia.revues.org/223.

Donadieu P, Fleury A. 1997. De l'agriculture périurbaine à l'agriculture urbaine. Courr. Environ. INRA 31: 45-61.

Dubost D. 2002. Écologie, aménagement et développement agricole des oasis algériennes. Algérie: CRSTRA Biskra.

Elloumi M. 2011. Agriculture périurbaine et nouvelles fonctions du foncier rural en Tunisie. In: Elloumi M, Jouve A-M, Napoléon E-C, Paoli J-C, eds. Régulation foncière et protection des terres agricoles en Méditerranée. Montpellier (France): CIHEAM (Options Méditerranéennes : Série B. Études et Recherches).

Imache A, Bouarfa S, Dionnet M, Kemmoun H, Hartani T, et al. 2009. Les arrangements de proximité sur les terres publiques : un choix délibéré ou "question de survie » pour l'agriculture irriguée en Algérie ? In: Actes du $4^{e}$ atelier régional du projet Sirma, Mostaganem (Algérie): Cirad. http:/hal.cirad.fr/SIRMA2008/ cirad-00366460v1.

Lavergne M. 2004. L'agriculture urbaine dans le bassin méditerranéen, une réalité ancienne à l'heure du renouveau. In: Masr $\mathrm{C}$, Padilla $\mathrm{J}$, eds. Interfaces : agricultures et villes à l'Est et au Sud de la Méditerranée, halshs-00638226.

Maachou H-M. 2012. Agriculture et paysage des espaces périurbains algériens. Projets de paysage 7, la revue scientifique sur la conception et l'aménagement de l'espace, rubrique « Enquêtes et débats ». http://www.projetsdepaysage.fr/fr/accueil [en ligne].

Trache S-M. 2010. Mobilités résidentielles et périurbanisation dans l'agglomération oranaise. Thèse de doctorat d'État, Université d'Oran, Algérie.

Cite this article as: Maachou HM, Otmane T. 2016. L'agriculture périurbaine à Oran (Algérie) : diversification et stratégies d'adaptation. Cah. Agric. 25: 25002. 